\title{
Cycle Time Models for the Bidirectional Flow-Rack AS/RS
}

Mohammed A. Hamzaoui

Ph.D student

University of Tlemcen

Manufacturing Engineering Laboratory of

Tlemcen

Algeria

Zaki. Sari

Full Professor

University of Tlemcen

Manufacturing Engineering Laboratory of

Tlemcen

Algeria

This paper deals with the bidirectional flow-rack AS/RS (Automated Storage and Retrieval System). This system was recently introduced in the literature. In this paper, models that consider the system from a holistic aspect are presented in order to grasp its real systemic running. The adopted modelling approach allows obtaining closed form and easy to use equations that model the expected required time to carry out storage/retrieval transactions for the whole system. The paper presents derived continuous models for these transaction. These latter are easy to use to perform mathematical investigations, as optimization, throughput evaluation, systems comparison etc. However, they are not completely faithful to the real system behavior. This is why also discrete models were developed, which are much more accurate, and which were used as a benchmark to evaluate the accuracy of the continuous ones. To do so, a self-made software was developed, and results could be extracted and discussed.

Keywords: AS/RS, Material handling, Warehousing• Mathematical modelling, Cycle time computation.

\section{INTRODUCTION}

Through the transmission of knowledge, and the perpetual evolution of science and technology, as well as the socio-cultural dynamics that animate our planet, the world evolved in all the dimensions. In today's day, we are in the era of technology, industrialization and globalization. New technologies, automation, artificial intelligences, modern engineering are strongly present in our daily life, particularly in the industrial and economic fields.

Many management tools, economic theories, high technologic equipment often see the light of day. At the cutting edge of technology, we can find automated storage and retrieval systems (AS/RS). These new systems, automate one of the most important activities in any company, which is warehousing. This kind of system acquit humans from the most painful operations related to this activity

These systems are very widespread in the industry, and widely studied from every angle by the scientific community.

These equipment offer a plurality of advantages, better exploitation of the storage area, organized inventory management thanks to the computerized control system, manpower reduction, flexibility in product types, more security and sureness for products and employees, lower operating costs, better production scheduling ... [1]. However, this does not prevent them from having limits and disadvantages, since their installation cost is quite high [2,3] and their layout

Received: June 2019, Accepted: August 2019

Correspondence to: Mohammed A. Hamzaoui, Ph.D

student, University of Tlemcen, Manufacturing

Engineering Laboratory of Tlemcen, Algeria

E-mail: hamzaoui.mohammed.adel@gmail.com

doi: $\mathbf{1 0 . 5 9 3 7 / f m e t 2 0 0 1 2 1 1 H}$

(C) Faculty of Mechanical Engineering, Belgrade. All rights reserved evolution constraints are quite unwieldy [1].

Furthermore, they are not suitable for all different types of products that are commonly stored in warehouses, and especially not for very large item assortments, since manual systems are often more flexible than automated systems, which is especially important in case of heterogeneous product portfolios. To the extent that current estimates suggest that up to $80 \%$ of order picking warehouses are operated manually [4].

Warehouses and AS/RS are therefore ones of the most important supply chain hotspots, since these latter play an important role in cushioning the effect of fluctuations in demand and hazards across the supply chain. As well as thanks to the development of new methods of management and new technologies, the economic players can afford to have more and more complex supply chains while still maintaining a relative control. Thanks to warehouse management methods, various aspects of the system's operation can be studied, while aiming at optimizing its overall functioning. As the development and evaluation of efficient storage policies or heuristic storage assignment [5-10], the implementation of interleaving policies and queue management $[11,12]$, batch size study and optimization in order picking operations $[13,14]$, development of analytical and simulation models [15-19] etc. Analytical modelling is precisely the subject of this paper, since it presents new mathematical models of a relatively recent AS/RS, the bidirectional flow-rack.

This latter is part of the flow-rack AS/RS family. These systems possess a deep rack composed of a multitude of bins provided by gravitational conveyors. The disposition of these bins, their shape and the number of machines allow having several types of flow-rack AS/RS. In the industry, the classical flow-rack AS/RS is typically used for one or very few types of items, where each bin is dedicated to a particular item and the system 
operates based on the first-in-first-out rule [17]. However, [7] evaluated the performance of an in-deep class based storage for this system (plurality of item types), and [17] investigated the performance of flow-rack AS/RS configurations considering a large mix of different product types. On the other hand, these systems, which are high-density storage systems, have low investment and operational costs [9]. Especially the free-fall-flow-rack AS/RS, which offers a considerable reduction of the initial investment. Thanks to the replacement of the $S / R$ machine by the combination between the free-fall movement and the transport conveyor for the retrieval of items [20]. This flow-rack system is used in the industry in the case of items with low size and weight, such as pharmaceutical products, food, textile, and electronic components [20]. In [21], while presenting the bidirectional flow -rack AS/RS, the authors have also proposed mathematical models of retrieval and dual cycle times, but by considering each machine separately according to a certain type of running. Nevertheless, what information about system performance can be obtained if the AS/RS is considered in a systemic approach? Namely, when the machines can run separately at times or collaboratively at other times, which should give more information about the throughput of the complete system when considered as a holistic entity. This paper presents new analytical models of single storage and retrieval cycle times for the entire system while considering $\mathrm{S} / \mathrm{R}$ machines-collaborative operation modes.

\section{LITERATURE REVIEW}

As mentioned above, AS/RS are studied according to different approaches and aiming at different objectives, whether they are strategic, tactical or operational. The design of new AS/RS variations or completely new AS/ RSs may be categorized as strategic goal-oriented research axe. This requires a lot of imagination and an increased systemic sense in order to propose coherent and efficient systems. We can mention the new warehouse technologies that are overcoming more operational constraints, such as compact rack AS/RSs and shuttle based $\mathrm{S} / \mathrm{R}$ systems. These latter were the object of several studies. [22] proposed a new type of flow-rack based system, which is composed of several bins with gravitational conveyors for depth movements and electric conveyors for transversal movements. [17] introduced some modifications to the classical flow-rack AS/RS to hold out with a brand-new system that needs only one S/R machine for storage and retrieval operations. [21] came up with a "mix" of the two previous cited systems to design a bidirectional flow-rack storage system (BDF AS/RS). It is a two $\mathrm{S} / \mathrm{R}$ machines based system, one on each face of the rack to perform both storage and retrieval operations.

Other researchers are interested in control and steering aspects, using innovative algorithms to manage these systems, testing new storage policies, or comparing performances of multiple systems configurations. [23] presented two metaheuristic algorithms (taboo search and simulated annealing) applied to the control of a flow rack automated storage/retrieval system to minimize the retrieval cycle time. The obtained results were compared to classical heuristics and analytical models found in the literature. [24] proposed travel-time model for class-based storage policies that describes the running of a unit load AS/RS which uses autonomous vehicle technology. [25] presented a simulation based regression analysis for rack configuration of an autonomous vehicle storage and retrieval system, they tried to find out the dependence between the inputs of the model (the number of tiers, aisles and bays) and the outputs (the average cycle time for storage and retrieval). [26] investigated location assignment and interleaving policy problems as if they were parts of a unique one, then proposed a two-step procedure and a taboo search algorithm to improve the solution for medium and large sized problems.

In the literature, a plurality of papers took interest on performance evaluation, systems comparison and design optimization. The commonly used tools are mathematical models and simulation models. [27] developed closed-form travel-time expressions for flow-rack automated storage and retrieval systems. Then they compared the continuous models to discrete accurate models to evaluate their precision. [28] determined the optimal dimensions for the single machine flow-rack AS/RS that minimize the travel time, using mathematical models developed in [17]. Then [29] proposed for the same AS/RS a parametric closed form cycle time model, and defined several optimal dimension regions. [20] developed continuous analytical models of expected retrieval-travel time for the free-fall flow-rack under a dedicated storage assignment policy. Then compared them for accuracy to the discrete developed models. [30] developed analytical models of the expected retrieval time for the flow-rack AS/RS. The proposed model is function of the physical parameters of the rack (high, length, depth) but also of the variety of the stored products and their proportion.

In addition to the flow-rack $\mathrm{AS} / \mathrm{RS}$, the $3 \mathrm{D}$ compact $\mathrm{AS} / \mathrm{RS}$ which is also a high-density system, was also investigated through many papers. In [31] analytical models of the expected travel time for the 3D compact AS/RS were developed. Then these models were used to perform optimization in order to find out optimal ratio between the three dimensions that minimize travel time. For the same system, [32] presented mathematical model of the dual cycle when the machine dwell point is in lower mid-point, then established the optimal system dimensions using these models. However, mathematical modelling is also used to evaluate performance of other AS/RS types than high-density storage systems. [33] developed analytical travel times for the multi-aisle AS /RS, by considering the operating characteristics of the storage and retrieval machine such as acceleration /deceleration and the maximum velocity. [34] questioned the broadly accepted assumption that an $\mathrm{m}$ aisles AS/RS can be modelled as $\mathrm{m}$ 1-aisle independent systems, and demonstrate that this could generate significant discrepancies. Kouloughli [1] presented analytical models for the multi-aisle and the mobile rack AS/RS, and then performed design optimization in order to decease the expected travel time. [36] also studied the same system, they presented travel time models for the order picking and proposed an efficient heuristic to quickly solve the nonlinear programming formulated optimization problem. 


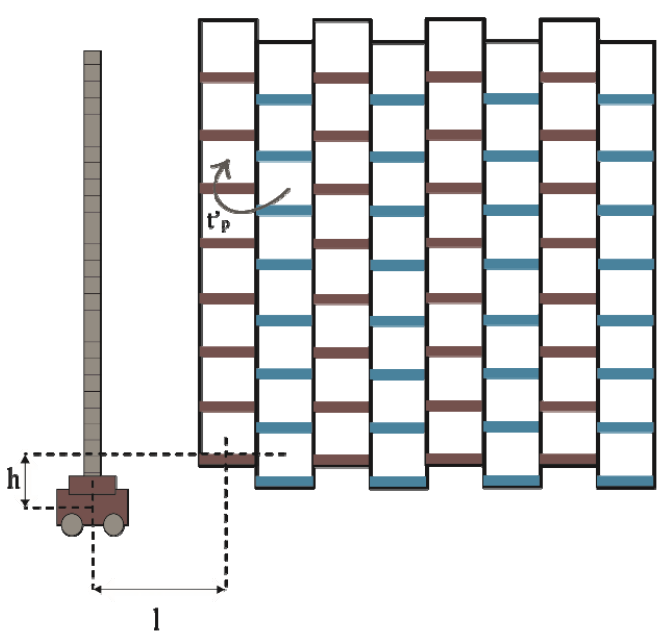

Front view

Figure 1. Bi-directional flow-rack AS/RS front and top views

Face B
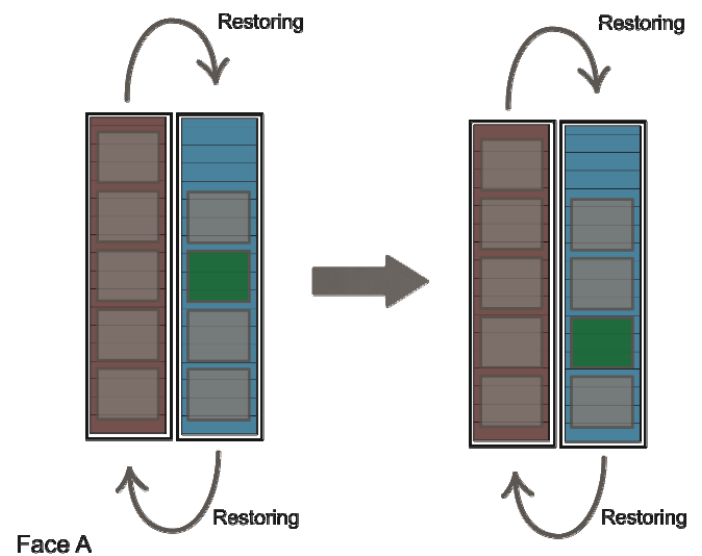

Figure 3. Blocking unit-load restoring

New warehouse technologies as the shuttle-based storage/retrieval systems (SBS/RS) [37] or the autonomous vehicle storage/retrieval systems (AVS/RS) were also investigated using these modelling tools. [38] developed analytical travel time models for the shuttlebased storage and retrieval system. They considered the operating characteristics of the elevators lifting table and the shuttle carrier, such as acceleration/deceleration and the maximum velocity. [39] also studied SBS/RS, they presented an analytical model-based tool that can estimate the mean and variance of travel time of lifts and shuttles, as well as the mean amount of energy consumption and energy regeneration per transaction. In [40] a simulation-based analysis is performed to evaluate the performance of the shuttle based storage system. Analytical cycle time models for the deep lane AVS/RS were developed by [41] while considering real operating characteristics of such a system. In addition to that, some researchers were also interested in multiobjective optimization, since [35] proposed multiobjective optimization models for the shuttle-based storage and retrieval system. Three objective functions

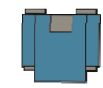

Working face B

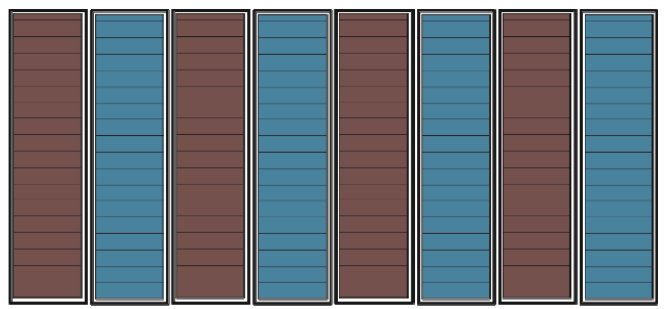

Working face $\mathrm{A}$

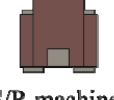

Top view
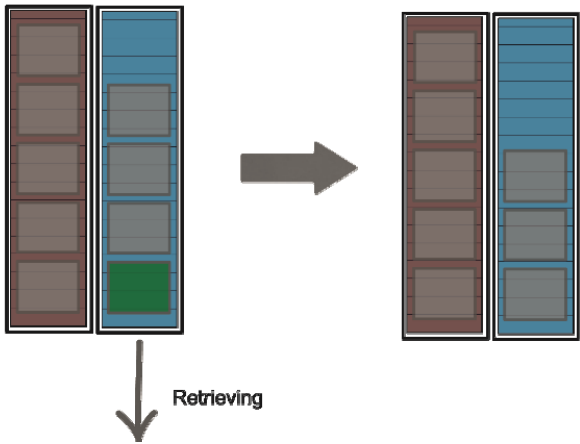

were considered in the design concept, which are the minimization of the average cycle time, amount of energy consumption and total investment cost. [42] were also interested in design optimization while minimizing three criteria, namely cycle time, cost and carbon footprint.

Thanks to the brief literature review below, it can be noticed that there are globally two types of flow-racks. Two-machines based flow-rack systems, where each machine is dedicated to one transaction type (to storage or retrieval) or single-machine based systems, where the only machine performs all operations. However, the bidirectional flow-rack $\mathrm{AS} / \mathrm{RS}$ is composed of two machines, which can do both operations, in addition to work independently or collaboratively in some cases (More details in Section 3). So in order to have a more precise idea of the system overall functioning, we should not stop at the machines travel time modelling, as it is the case for some AS/RS. We should rather consider the system in its holistic aspect, in order to obtain the expected cycle times of the entire system taking into account its different operation modes. 
As far as we know, even if this system has been often cited in many papers to position investigation works related to flow-racks, this latter has not been studied to perform such investigations. [43,44] remains to this day the only instigations on the bi-directional flow-rack after its introduction in [21]. In [43] the presented study was to propose a batching-greedy heuristic to generate dual-command operations in the bidirectional flow-rack AS/RS. Whereas in [44] a threestep heuristic is designed, which includes Grouping Matching Sequencing, for the storage assignment and operation generation in the studied system with Duration Of Stay storage policy.

This paper presents analytical models of storage and retrieval cycle times for the bidirectional flow-rack AS/ RS while considering the holistic aspect of the system running. Then discrete models of these cycle times are also developed to be used as a benchmark for accuracy evaluation of the continuous ones through simulation. The simulation is performed via a self-made software whom functioning principle will be presented in the following sections.

\section{STUDIED SYSTEM}

As mentioned before, thanks to the plurality of research fields in this domain, several types of AS/RSs could see the light of day over the years. In this paper, the bidirectional flow-rack AS/RS was chosen to be the object of these investigations. This new system, as mentioned above, was recently introduced in [21]. The main characteristic of this system is the structure of its rack. It has a set of superimposed bins, placed side by side, that lean alternately towards the two rack sides, in addition to the two $\mathrm{S} / \mathrm{R}$ machines, one on either side (Fig. 1.). This architectural approach, keeps the advantage of a Ushaped locker as in the single machine flow rack AS/RS [17] while eliminating the hairpin bend (which is mechanically difficult to achieve, because of the tricky product sliding). Since in this case, the item displacement from a bin to the one that is paired with (change of direction), is performed by the secondary machine. Therefore, contrary to the 3-Dimensional compact AS/RS [22], it is no longer necessary to have electrical conveyors to link every two paired bins.

This modification in the bins orientation, and the restoring conveyor elimination, compared to a classical flow-rack AS/RS, allows it to greatly surpass this latter in terms of performance (cycle time) and cost (acquisition and use). In addition to this, storage and retrieval operations can be done in both of the two rack sides, contrary to the single machine flow-rack AS/RS, where there is only one side for the two operations, and the classical flow-rack AS/RS where each side is dedicated to only one operation type.

Since this system is recent, and seems to be very efficient compared to its predecessors, it would be interesting to examine this system in order to be compared with other AS/RS types and to know how this system can be efficiently used. [21] presented mathematical models of the machines expected travel times. They determined the expected number of blocking items for a retrieval operation, and based on this calculation pre- sented expected travel times for each machine to perform a storage, a retrieval, or an independent dual cycle (without the help of the secondary machine). That said, the models that are proposed in this paper, take the overall system running into consideration while still considering the particular functioning of each machine. Since the S/R machines may work together or independently, this influences the system overall throughput. The modelling is done in such a manner to simplify its elaboration, and come out with generic models that summarize the overall system functioning.

To do so, we consider the overall system running, through mathematical formulation, in order to obtain analytical equations that give us information as well as tools to carry out investigations breakouts. The continuous cycle time mathematical models provide us with these exploration possibilities, especially when it comes to performance studies, optimization, and decision making, mainly at a strategic level. In this paper, continuous mathematical models for storage and retrieval will be presented. However, even if these equations give us the ability to use them quite easily when it comes to mathematical manipulations during investigations, they are not completely faithful to the actual system operation. Since they are based on a set of approximations that make the modeling of this kind of complex systems possible. Moreover, it is also possible to model these systems using a discrete approach. This latter consists on the elaboration of discrete equations that are more faithful to the system behavior than the continuous ones. That said, due to their complexity, these equations cannot neither be used to evaluate system performance nor for analytical optimization or other complex mathematical investigations. It is for these reasons that these discrete models are used as a benchmark for the continuous ones, by evaluating the gap between them using simulation. Since in this paper, continuous models are going to be derived and presented, also discrete models will be calculated and the different followed steps displayed. After that, a simulation for gap evaluation will be conducted, before presenting results and discussions, through which, the accuracy of the continuous models will be discussed.

\section{MATHEMATICAL MODELLING}

In this section, discrete and continuous models are presented, the modelling was done following a couple of assumptions. The assumptions were determined by the operating characteristics of the system as defined in [21] and simplification of some physical phenomena as the consideration of constant velocities. That said, the considered operating characteristics of the system represent the normal operating mode of the system for storage and retrieval operations.

\section{Assumptions:}

$\mathrm{A}_{1}$-Machine 1 stores on odd columns and retrieves on even ones (conversely for Machine 2).

$\mathrm{A}_{2}$-The system has two operating modes for retrieval, since when the item to be retrieved is not on the first position, the two machines work together, as defined by [21] when they presented the system.

$\mathrm{A}_{3}$-Storage and retrieval locations are considered to be uniformly distributed (random storage policy). 
$\mathrm{A}_{4}$-The machines dwell points are located in the $\mathrm{P} / \mathrm{D}$ stations. They are situated at the bottom corner of the rack, one in front of the other (Fig 2).

$\mathrm{A}_{5}$-The machines velocities are considered constant.

\subsection{Discrete approach}

The average exact time of storage/retrieval can be obtained by summing the storage/retrieval travel times of all locations, and then divide this sum by the number of locations [45] (Uniform distribution is considered $\mathrm{A}_{3}$ ). Based on this assumption, the discrete models for storage and retrieval operations in the system under consideration are going to be derived.

First, we consider the two sides of our system as two matrices, where each element represents a bin. The horizontal and vertical subscripts of the matrix represent the coordinates of the bins. Moreover the pickup /delivery stations (which are at the same time the dwell points of the machines) are assumed to be in the same side of the rack for the two machines (one in front of the other). That way, the closest bin to machine 1 is used for storage, whereas, for machine 2 it is used for retrieval (Fig. 2.).

\section{A-The storage:}

The system comprises two identical machines, which in the case of storage work in a completely independent way. Hence, this is equivalent to a station with two parallel machines. At this moment, the whole station capacity (the whole system) will be the sum of the two machines capacities:

$$
C S C^{D}=C S C_{\text {Machine 1 }}^{D}+C S C_{\text {Machine 2 }}^{D}
$$

Then the expected storage cycle time of the whole system will be:

$$
E S C^{D}=\frac{E S C_{\text {Machine 1 }}^{D} \cdot E S C_{\text {Machine 2 }}^{D}}{E S C_{\text {Machine 1 }}^{D}+E S C_{\text {Machine 2 }}^{D}}
$$

On the other hand (Appendix A):

$$
\begin{gathered}
E S C_{\text {Machine 1 }}^{D}=\frac{2}{N_{h} N_{l}} \sum_{i=1}^{\frac{N_{l}}{2}} \sum_{j=1}^{N_{h}} 2 \max \left((2 i-1) t_{h}^{\prime} ; j t_{v}^{\prime}\right) \\
\left.E S C_{\text {Machine 2 }}^{D}=\frac{2}{N_{h} N_{l}} \sum_{i=1}^{\frac{N l}{2}} \sum_{j=1}^{N h} 2 \max \left(2 i t_{h}^{\prime} ; j t_{v}^{\prime}\right)\right)
\end{gathered}
$$

Finally:

$$
\begin{aligned}
& E S C^{D}=\frac{4}{N h \cdot N l}\left(\sum_{i=1}^{\frac{N l}{2}} \sum_{j=1}^{N h} \max \left(2 i t_{h}^{\prime} ; j t_{v}^{\prime}\right)\right) \\
& \left(\frac{\sum_{i=1}^{\frac{N l}{2}} \sum_{j=1}^{N h} \max \left((2 i-1) t_{h}^{\prime} ; j t_{v}^{\prime}\right)}{\sum_{i=1}^{N l} \sum_{j=1}^{N h} \max \left(i t_{h}^{\prime} ; j t_{v}^{\prime}\right)}\right)
\end{aligned}
$$

\section{B-The retrieval:}

For a retrieval, the two $\mathrm{S} / \mathrm{R}$ machines may, sometimes work independently, and other times work together. When the desired item is on the first position, the concerned machine travels to the concerned bin and retrieves the product directly. On the other hand, when the product to be retrieved is not on the first position, the two machines have to work together; one proceeds to the retrieval of the product (in addition to displacing the blocking products), and the second performs the transfer of the products from one bin to another (between the two paired bins). So that the desired item can be accessible for the concerned machine (Fig. 3.).

It appears clearly that the whole system has two operating modes when it is about retrieval operations, depending on the desired product position. When this latter is in the first position, the machines work independently, and as for the storage, the system is analog to a two parallel machines station. That said, when the product to be retrieved is not in the first position, the machines work together and the retrieval time of the system is the retrieval time of the retrieving machine. Since the uniform storage policy is considered, all the products have the same probability to be retrieved, which means that the machines 1 and 2 have the same probability to be the retrieving machine (and the other will be the assisting machine). Let OP1 and OP2 be the two operating modes as explained above, so:

OP1: The machines work independently (product on the first position).

OP2: The machines work together (product is not on the first position).

Knowing the two operating modes of the system, the occurring probability of these two modes needs to be found. $M$ is the number of products that can be stored in one bin, and $\rho$ is the load rate, since the uniform distribution is considered, $\rho M$ is the average number of products stored in each bin of the system. On the other hand, the first operating mode occurs only when the desired item is in the first position, which means in $\frac{1}{\rho_{M}}$ of the cases, consequently it can be written that:

$$
E R C^{D}=\frac{1}{\rho M} E R C_{O P 1}^{D}+\left(1-\frac{1}{\rho M}\right) E R C_{O P 2}^{D}
$$

Concerning the first operating mode, as it was explained, this case is similar to storage transactions, hence:

$$
E R C_{O P 1}^{D}=\frac{E R C_{O P 1 / \text { Machine } 1}^{D} \cdot E R C_{O P 1 / \text { Machine } 2}^{D}}{E R C_{O P 1 / \text { Machine } 1}^{D}+E R C_{O P 1 / \text { Machine } 2}^{D}}
$$

On the other hand, as it was mentioned before, in the second operating mode, the two machines have the same probability to be the retrieving machine, and the retrieval time of the whole system equals the retrieval time of the retrieving machine:

$$
E R C_{O P 2}^{D}=\frac{1}{2}\left(E R C_{O P 2 / \text { Machine } 1}^{D}+E R C_{O P 2 / \text { Machine } 2}^{D}\right)
$$

Moreover, the machines retrieval times are (Appen$\operatorname{dix} B)$ : 


$$
\begin{aligned}
& E R C_{O P 1 / \text { Machine } 1}^{D}=\frac{2}{N h N l} \sum_{i=1}^{N l} \sum_{j=1}^{N h} 2 \max \left(2 i t_{h}^{\prime} ; j t_{v}^{\prime}\right) \\
& E R C_{O P 1 / \text { Machine } 2}^{D}=\frac{2}{N h N l} \sum_{i=1}^{\frac{N l}{2}} \sum_{j=1}^{N h} 2 \max \left((2 i-1) t_{h}^{\prime} ; j t_{v}^{\prime}\right) \\
& E R C_{O P 2 / \text { Machine } 1}^{D}=\frac{2}{N h N l} \sum_{i=1}^{N} \sum_{j=1}^{N h}\left(2 \max \left(2 i t_{h}^{\prime} ; j t_{v}^{\prime}\right)+\right. \\
& \left.+m_{2 i ; j} \max \left(t_{h}^{\prime} ; t_{v}^{\prime}\right)\right) \\
& E R C_{O P 2 / \text { Machine } 2}^{D}=\frac{2}{N h N l} \sum_{i=1}^{\frac{N l}{2}} \sum_{j=1}^{N h}\left(2 \max \left((2 i-1) t_{h}^{\prime} ; j t_{v}^{\prime}\right)+\right. \\
& \left.+m_{2 i-1 ; j} \max \left(t_{h}^{\prime} ; t_{v}^{\prime}\right)\right)
\end{aligned}
$$

Therefore by replacing (9) and (10) in (7):

$$
\begin{aligned}
& E R C_{O P 1}^{D}=\frac{4}{N h \cdot N l}\left(\sum_{i=1}^{\frac{N l}{2}} \sum_{j=1}^{N h} \max \left(2 i t_{h}^{\prime} ; j t_{v}^{\prime}\right)\right) . \\
& >\left(\frac{\sum_{i=1}^{\frac{N l}{2}} \sum_{j=1}^{N h} \max \left((2 i-1) t_{h}^{\prime} ; j t_{v}^{\prime}\right)}{\sum_{i=1}^{N l} \sum_{j=1}^{N h} \max \left(i t_{h}^{\prime} ; j t_{v}^{\prime}\right)}\right)
\end{aligned}
$$

Moreover (Appendix C):

$$
E R C_{O P 2}^{D}=\frac{1}{N h N l} \sum_{i=1}^{N l} \sum_{j=1}^{N h}\left(2 \max \left(i t_{h}^{\prime} ; j t_{v}^{\prime}\right)+m_{i ; j} \max \left(t_{h}^{\prime} ; t_{v}^{\prime}\right)\right)
$$

Finally by replacing (13) and (14) in (6):

$$
E R C^{D}=\frac{1}{N_{h} N_{l}}\left(\begin{array}{l}
\left(\frac{4}{\rho M} \sum_{i=1}^{\frac{N_{l}}{2} \sum_{j=1}^{N_{h}} \max \left((2 i-1) t_{h}^{\prime} ; j t_{v}^{\prime}\right)}\right) . \\
\left(\begin{array}{l}
\sum_{i=1}^{\frac{N l}{2}} \sum_{j=1}^{N h} \max \left(2 i t_{h}^{\prime} ; j t_{v}^{\prime}\right) \\
\sum_{j=1}^{N h} \max \left(i t_{h}^{\prime} ; j t_{v}^{\prime}\right)
\end{array}\right)+ \\
\left(1-\frac{1}{\rho M}\right)\left(\begin{array}{l}
\sum_{i=1}^{N l} \sum_{j=1}^{N h}\left(2 \max \left(i t_{h}^{\prime} ; j t_{v}^{\prime}\right)+\right. \\
\left.+m_{i ; j} \max \left(t_{h}^{\prime} ; t_{v}^{\prime}\right)\right)
\end{array}\right)
\end{array}\right)
$$

where $\sum_{i=1}^{N_{l}} \sum_{j=1}^{N_{h}} m_{i j}=[\rho . N] \approx \rho . N$

Therefore:

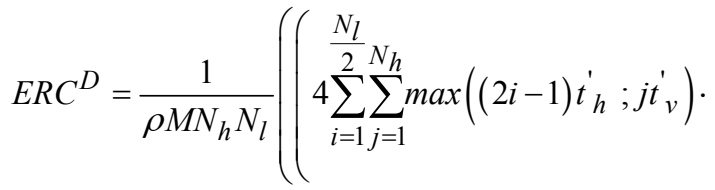

$$
\begin{aligned}
& \left(\frac{\sum_{i=1}^{\frac{N l}{2}} \sum_{j=1}^{N h} \max \left(2 i t_{h}^{\prime} ; j t_{v}^{\prime}\right)}{\sum_{i=1}^{N l} \sum_{j=1}^{N h} \max \left(i t_{h}^{\prime} ; j t_{v}^{\prime}\right)}\right)+(\rho M-1) . \\
& \left(\sum_{i=1}^{N l} \sum_{j=1}^{N h}\left(2 \max \left(i t_{h}^{\prime} ; j t_{v}^{\prime}\right)+m_{i ; j} \max \left(t_{h}^{\prime} ; t_{v}^{\prime}\right)\right)\right)
\end{aligned}
$$

Finally:

$$
\begin{aligned}
& E R C^{D}=\frac{1}{\rho M N_{h} N_{l}}\left(\left(4 \sum_{i=1}^{\frac{N_{l}}{2} \sum_{h=1} \max }\left((2 i-1) t_{h}^{\prime} ; j t_{v}^{\prime}\right) .\right.\right.
\end{aligned}
$$

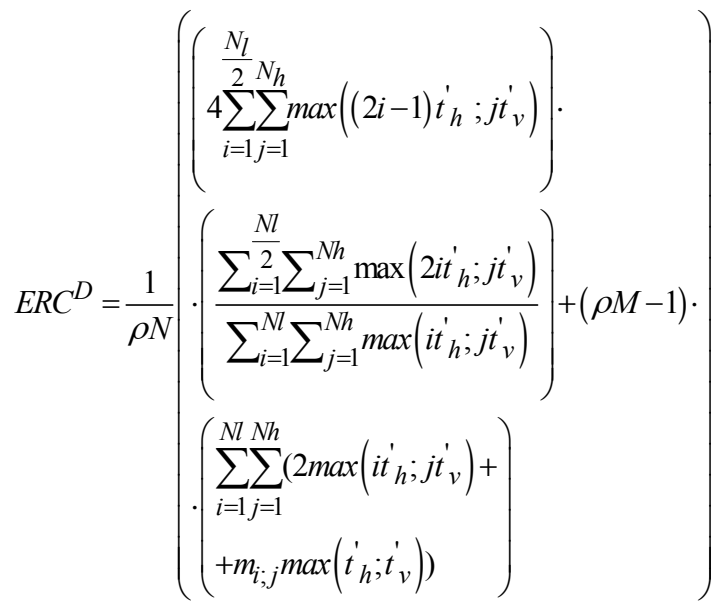

where $\sum_{i=1}^{N_{l}} \sum_{j=1}^{N_{h}} m_{i j}=[\rho . N] \approx \rho . N$

\subsection{Continuous approach}

As mentioned earlier, discrete modeling is more faithful to the real system behavior compared to the continuous one; however, this latter is also used to model this kind of systems, since this approach can be very relevant and may facilitate the implementation of further mathematical investigations.

In the continuous approach, it is assumed that the two rack faces are a surface grouping an infinity of points, so that each point can be a storage or retrieval location. When [45] studied a unit load AS/RS, they demonstrated that the average time taken by an $\mathrm{S} / \mathrm{R}$ machine to go from its dwell point (in one of the rack's corners) to any other point of the rack's face is:

$$
E\left(V_{1}\right)=\frac{T}{2}\left(\frac{b^{2}}{3}+1\right)
$$

This remains true for our system, so we will from there, build our modeling of the storage and retrieval cycle times.

A-The storage:

In the case of a simple storage transaction, the only movements made by the $\mathrm{S} / \mathrm{R}$ machines are in fact just a round trip, (from the P/D station to the storage bin, then a return from this bin to the $\mathrm{P} / \mathrm{D}$ station). 
The system comprises two identical machines, which in the case of storage; work in a completely independent way. Hence, this is equivalent to a station with two parallel machines. At this moment, the whole station capacity (the whole system) will be the sum of the two machines capacities:

$$
C S C^{C}=\operatorname{CSC}_{\text {Machine } 1}^{C}+\operatorname{CSC}_{\text {Machine } 2}^{C}
$$

Then the expected storage cycle time of the whole system will be:

$$
E S C=\frac{E S C_{\text {Machine 1 }}^{C} \cdot E S C_{\text {Machine 2 }}^{C}}{E S C_{\text {Machine 1 }}^{C}+E S C_{\text {Machine 2 }}^{C}}
$$

On the other hand we have (Appendix D):

$$
\begin{aligned}
& E S C_{\text {Machine 1 }}^{C}=T\left(\frac{b^{2}}{3}+1\right) \\
& E S C_{\text {Machine 2 }}^{C}=T\left(\frac{b^{2}}{3}+1\right)
\end{aligned}
$$

Since the machines average storage times are equal, the throughput is simply doubled (Appendix D):

$$
E S C C^{C}=\frac{T}{2}\left(\frac{b^{2}}{3}+1\right)
$$

\section{B-The retrieval:}

Unlike storage operations, a retrieval requires additional manipulations to be performed, particularly when the product to be retrieved is not in the first position. Moreover, each machine is not requested only when the retrieval concerns this machine especially. Since it is used even when the transaction concerns the other machine, in order to transfer the products from one bin to another. It is therefore necessary that this usage should be taken into consideration during the modeling, since in steady state; these operations must be counted as a time of use.

First, when looking at each machine apart, the retrieval includes:

- A go from the P/D station to the retrieval location (first half of the round trip).

- Desired item recuperation.

- A return from the retrieval location to the $\mathrm{P} / \mathrm{D}$ station (second half of the round trip).

In the same way as for discrete models, we need to distinguish two cases:

OP1: The machines work independently (product on the first position).

OP2: The machines work together (product is not on the first position).

It can be noticed that the first and the last travels can be combined in a single round trip, so the expected retrieval time for machine 1 can be wrote as:

$$
E R C_{\text {Machine } 1}^{C}=E(R T)+E\left(V_{2}\right)
$$

where $E(R T)$ is the round trip expected time and $E\left(V_{2}\right)$ is the expected time to reach the desired item.

As in storage, this round trip travel time equals:

$$
E(R T)=2 E\left(V_{1}\right)
$$

However, unlike OP2, in OP1 all the retrieval operations are just a simple round trip, for more precision we write:

$$
\begin{aligned}
& E R C_{O P 1 / \text { Machine } 1}^{C}=2 E\left(V_{1}\right) \\
& E R C_{O P 2 / \text { Machine } 1}^{C}=2 E\left(V_{1}\right)+E\left(V_{2}\right)
\end{aligned}
$$

On the other hand, in OP2 the position of the desired item defines the number of successive retrievals and storages (restoring) to be made so that the desired product can be accessible, and thus the number of round trips between two paired bins. The mean time of such a maneuver is modeled by the arithmetic mean of all the times that this operation may require (all the possibilities).

- For a product on the first position (OP1), the required time is:

$$
T(\text { Restoring })=0
$$

- For a product on the second position, the required time is:

$$
T(\text { Restoring })=2 t^{\prime} p
$$

- For a product on the third position, the required time is:

$T($ Restoring $)=4 t^{\prime}$

- For a product on the $\mathrm{m}^{\text {th }}$ position, the required time is: $T($ Restoring $)=2(m-1) t^{\prime} p$

- The average required time is:

$$
E\left(V_{2}\right)=\frac{1}{\left(M^{\prime}-1\right)} \sum_{m=2}^{M^{\prime}} 2(m-1) t_{p}^{\prime}
$$

where $M^{\prime}$ is the number of items in the considered bin.

Therefore:

$$
\begin{aligned}
& E\left(V_{2}\right)=\frac{2 t_{p}^{\prime}}{\left(M^{\prime}-1\right)} \sum_{m=2}^{M^{\prime}}(m-1) \\
& E\left(V_{2}\right)=\frac{2 t_{p}^{\prime} p}{\left(M^{\prime}-1\right)} \sum_{m=1}^{M^{\prime}-1} m
\end{aligned}
$$

Since we have an arithmetic series:

$$
E\left(V_{2}\right)=\frac{2 t^{\prime} p\left(M^{\prime}-1\right) M^{\prime}}{2\left(M^{\prime}-1\right)}
$$

Finally:

$$
E\left(V_{2}\right)=M^{\prime} t^{\prime} p
$$

Replacing (18) and (32) in (26) and (27):

$$
\begin{aligned}
& E R C_{O P 1 / \text { Machine } 1}^{C}=T\left(\frac{b^{2}}{3}+1\right) \\
& E R C_{O P 2 / \text { Machine } 1}^{C}=T\left(\frac{b^{2}}{3}+1\right)+M^{\prime} t^{\prime}{ }_{p}
\end{aligned}
$$


Following the same steps for machine 2:

$$
\begin{aligned}
& E R C_{O P 1 / \text { Machine } 2}^{C}=T\left(\frac{b^{2}}{3}+1\right)+M^{\prime} t^{\prime}{ }_{p} \\
& E R C_{O P 2 / \text { Machine } 2}^{C}=T\left(\frac{b^{2}}{3}+1\right)+M^{\prime} t_{p}^{\prime}
\end{aligned}
$$

Now we need to focus on the holistic system behavior, considering the two operation modes of the machines, and their impact on the global functioning of the system. Following the same reasoning as for the discrete modeling:

We have that $M$ is the bin size, and the uniform distribution is considered, so the average number of stored items is $M^{\prime}$, where $M^{\prime}=\rho M$. On the other hand, thanks to the uniform distribution, the probability to retrieve any item of the bin (especially the first one) is $\frac{1}{M^{\prime}}$. Then we can conclude that the probability to retrieve an item on the first position (OP1) is $\frac{1}{M^{\prime}}$ and the probability to retrieve an item which is not on the first position (OP2) is $\left(1-\frac{1}{M^{\prime}}\right)$.

This means that for the whole system we can write:

$$
E R C^{C}=\frac{1}{M^{\prime}} E R C_{O P 1}^{C}+\left(1-\frac{1}{M^{\prime}}\right) E R C_{O P 2}^{C}
$$

For the first operating mode OP1, since the two machines work in an independent way, the system is comparable to a two parallel machines unit, where the global capacity equals the sum of the machines capacities:

$$
C R C_{O P 1}^{C}=C R C_{O P 1 / \text { Machine } 1}^{C}+C R C_{O P 1 / \text { Machine } 2}^{C}
$$

where:

$$
\begin{aligned}
& C R C_{(O P 1 / \text { Machine })}^{C}=1 /\left(E R C_{(O P 1 / \text { Machine })}^{C}\right)(\text { Itembytimeunit }) \\
& C R C_{(O P 1 / \text { Machine } 2)}^{C}=1 /\left(E R C_{(O P 1 / \text { Machine } 2)}^{C}\right)(\text { Itembytimeunit })
\end{aligned}
$$

Then the expected retrieval cycle time of the whole system will be:

$$
E R C_{O P 1}^{C}=\frac{E R C_{O P 1 / \text { Machine } 1}^{C} \cdot E R C_{O P 1 / \text { Machine } 2}^{C}}{E R C_{O P 1 / \text { Machine } 1}^{C}+E R C_{O P 1 / \text { Machine } 2}^{C}}
$$

Since the machines average retrieval times are equal (In OP1), as for the storage the throughput is simply doubled (Appendix D):

$$
E R C_{O P 1}^{C}=\frac{T}{2}\left(\frac{b^{2}}{3}+1\right)
$$

For the second operating mode OP2, the two machines are working together, and the global expected retrieval time of the system equals the retrieval time of the retrieving machine. On the other hand, since the uniform distribution is considered, the two machines have the same probability of being solicited for a retrieval.
That means that the mean retrieval time of the system equals the average of the two machines retrieval times:

$$
E R C_{O P 2}^{C}=\frac{1}{2}\left(E R C_{O P 2 / \text { Machine } 1}^{C}+E R C_{O P 2 / \text { Machine } 2}^{C}\right.
$$

Replacing (34) and (36) in (43):

$$
E R C_{O P 2}^{C}=T\left(\frac{b^{2}}{3}+1\right)+M^{\prime} t^{\prime} p
$$

Replacing (42) and (44) in (37):

$$
\begin{aligned}
& E R C^{C}=\frac{1}{M^{\prime}} \frac{T}{2}\left(\frac{b^{2}}{3}+1\right)+\left(1-\frac{1}{M^{\prime}}\right) \\
& \left(T\left(\frac{b^{2}}{3}+1\right)+M^{\prime \prime} t_{p}^{\prime}\right)
\end{aligned}
$$

After simplifications (Appendix E):

$$
E R C^{C}=\frac{T}{\rho M}\left(\frac{b^{2}}{3}+1\right)\left(\frac{2 \rho M-1}{2}\right)+(\rho M-1) t_{p}^{\prime}
$$

As mentioned before, the continuous models (23) and (46) were developed in order to perform further investigations on the studied system (performance evaluation, analytical optimization, systems comparison ...). On the other hand, the discrete models (5) and (17) will be used in this paper to evaluate the accuracy of the continuous ones. To do so, a simulation was conducted, while investigating different systems sizes, shape factors and several load rates. More details will be presented in the next section.

\section{NUMERICAL STUDY}

As mentioned at the end of the previous section, the continuous models need to be compared to the discrete ones in order to evaluate their accuracy. This is due to the fact that the continuous modelling is based on some approximations while the discrete models remain more faithful to the actual system operation. These latter, are going to be used as a benchmark for the continuous models, the comparison is performed using simulation, in order to evaluate the gap between the two models. To do so, a self-made software has been developed. In the sequel we will present the main operating principles of the conducted simulation.

1-Input data:

To perform our simulation we need a couple of input data that determine operating aspect of the system. In our case, the needed data are the system dimensions $\left(\mathrm{N}_{1}\right.$; $\mathrm{N}_{\mathrm{h}}$; M), the machines velocities and the load rate. Concerning the system dimensions, we decided to investigate a set of system sizes while varying the shape factor. So we chose three different sizes (with a tolerated size variation percentage) $400 \pm 1 \%$ (Table 1), $2000 \pm 1 \%$ (Table 2) and $10000 \pm 1 \%$ (Table 3 and 4) and for each one of them we chose different configurations that vary the shape factor value from small to almost square in time system $(b \approx 1)$, while also varying the depth of the bins. We end up with 28 
configuration that are displayed in Tables 1-4. Moreover, concerning the machines velocities we affect the value 1 to $\mathrm{t}^{\prime}{ }_{\mathrm{h}}$ and $\mathrm{t}_{\mathrm{v}}$, which means that the machines travel horizontally or vertically from one bin to the adjacent one in 1 unit of time. Finally, we vary the load rate from a low value $(0.3)$ to the maximum it can reach 1. However the zone of actual operation for the system is defined as the interval $\rho \in[0.7 ; 0.85]$ [27].

\section{2-Processing:}

It represents the main part of the conducted simulation. This latter is performed in order to compare between the two modellings, the discrete models take into consideration all the possible cases while continuous ones need a limited number of parameters to be calculated. For this reason, our simulation program generates all the happenable transactions demands (storage/retrieval) according to the input data.

The program consider a system size according to the dimensions in the input data, then the system is filled depending on the load rate and following a uniformly distributed probability on the storage locations.

Thanks to all generated storage and retrieval events the global average cycle times are calculated using the discrete models. This operation is repeated for a large number of instances (10000 times).

Then the continuous models are calculated thanks to the input data, since only system dimensions, machines velocities and the load rate are needed.

3-Output data:
At the end the values of the two modelling are compared and a percent error calculated. Since the gap evaluation is the main goal of this comparison, and due to the lack of space, only the error value is presented in the result tables. Moreover, in this case, when taken separately, the values of the cycle times do not give essential information, but the interest is in the fact of comparing them with other models of other systems for example, but following the same conditions of measures units or normalization of the input data. This is why only the relevant information (which is the error) is presented in the result tables since there is no need to display the cycle time values.

In order to confirm that our program is working properly, we started by testing it on small instances whose calculation can be checked by hand before going to larger instances. After a few hours of calculation, the simulation gave a set of results, which were summarized in Tables 1-4. These tables show the percentage errors, which exist between the discrete and continuous models.

What is remarkable in these tables is that errors relating to ESC require only one line (at the bottom of each table). This is due to the fact that storage operations are not depending on the system load rate, since regardess of the system load rate, a storage in any bin will always take the same time. Therefore, only one comparison per configuration is necessary. Consequently, the variation changes only when the shape factor or the bins depth change (which change for each different configuration).

Table 1. ESC and ERC percent error for system of 400 storage locations

\begin{tabular}{|c|c|c|c|c|c|c|c|c|}
\cline { 2 - 9 } \multicolumn{1}{c|}{} & \multicolumn{7}{|c|}{ Percent error between discrete and continuous retrieval times Error(RC) } \\
\hline $\mathrm{M}$ & \multicolumn{3}{|c|}{4} & \multicolumn{5}{c|}{8} \\
\hline$(\mathrm{Nl} ; \mathrm{Nh})$ & $(33 ; 3)$ & $(12 ; 8)$ & $(9 ; 11)$ & $(10 ; 10)$ & $(3 ; 17)$ & $(13 ; 4)$ & $(5 ; 10)$ & $(7 ; 7)$ \\
\hline $\mathrm{b}$ & 0.091 & 0.666 & 0.818 & 1 & 0.176 & 0.307 & 0.5 & 1 \\
\hline$\rho$ & 0.181 & 2.625 & 3.992 & 3.610 & 3.718 & 1.039 & 4.285 & 3.501 \\
\hline 1 & 1.923 & 4.193 & 5.507 & 5.218 & 4.084 & 1.321 & 4.757 & 3.906 \\
\hline 0.9 & 3.129 & 5.230 & 6.620 & 6.300 & 4.456 & 1.603 & 5.070 & 4.100 \\
\hline 0.85 & 4.524 & 6.376 & 7.840 & 7.483 & 4.758 & 1.945 & 5.420 & 4.495 \\
\hline 0.8 & 6.016 & 7.886 & 9.185 & 8.810 & 5.251 & 2.355 & 5.855 & 4.968 \\
\hline 0.75 & 7.500 & 9.309 & 10.485 & 10.261 & 5.692 & 2.683 & 6.346 & 5.342 \\
\hline 0.7 & 11.188 & 12.457 & 13.809 & 13.525 & 7.039 & 3.972 & 7.649 & 6.552 \\
\hline 0.6 & 15.261 & 16.286 & 17.517 & 17.115 & 9.069 & 5.910 & 9.594 & 8.567 \\
\hline 0.5 & 19.057 & 19.771 & 20.865 & 20.638 & 11.870 & 8.604 & 12.476 & 11.337 \\
\hline 0.4 & 21.443 & 21.243 & 22.583 & 22.396 & 16.327 & 13.298 & 16.827 & 15.552 \\
\hline 0.3 & 0.022 & 0.738 & 2.731 & 3.718 & 4.643 & 0.0254 & 5.084 & 2.372 \\
\hline Error(SC) $\rightarrow$ & & & & &
\end{tabular}

Table 1. $E(S C)$ and $E(R C)$ percent error for systems 2000 storage locations

\begin{tabular}{|c|c|c|c|c|c|c|c|c|}
\hline & \multicolumn{8}{|c|}{ Percent error between discrete and continuous retrieval times Error $(\mathrm{RC})$} \\
\hline $\mathrm{M}$ & \multicolumn{4}{|c|}{10} & \multicolumn{4}{|c|}{40} \\
\hline (N1;Nh) & $(4 ; 50)$ & $(25 ; 8)$ & $(10 ; 20)$ & $(14 ; 14)$ & $(3 ; 17)$ & $(5 ; 10)$ & $(6 ; 8)$ & $(7 ; 7)$ \\
\hline$\frac{b}{\rho}$ & 0.08 & 0.32 & 0.5 & 1 & 0.176 & 0.5 & 0.75 & 1 \\
\hline 1 & 1.620 & 0.717 & 2.593 & 2.224 & 1.622 & 1.578 & 1.429 & 1.237 \\
\hline 0.9 & 1.910 & 0.966 & 2.891 & 2.510 & 1.752 & 1.718 & 1.560 & 1.351 \\
\hline 0.85 & 2.096 & 1.138 & 3.086 & 2.698 & 1.825 & 1.798 & 1.634 & 1.415 \\
\hline 0.8 & 2.321 & 1.344 & 3.312 & 2.917 & 1.903 & 1.884 & 1.715 & 1.486 \\
\hline 0.75 & 2.584 & 1.583 & 3.573 & 3.175 & 1.988 & 1.980 & 1.805 & 1.564 \\
\hline 0.7 & 2.902 & 1.873 & 3.891 & 3.480 & 2.081 & 2.085 & 1.904 & 1.650 \\
\hline 0.6 & 3.771 & 2.685 & 4.742 & 4.309 & 2.297 & 2.334 & 2.138 & 1.855 \\
\hline 0.5 & 5.141 & 3.990 & 6.085 & 5.623 & 2.566 & 2.654 & 2.442 & 2.121 \\
\hline 0.4 & 7.487 & 6.257 & 8.329 & 7.858 & 2.922 & 3.086 & 2.858 & 2.486 \\
\hline 0.3 & 11.658 & 10.311 & 12.300 & 11.792 & 3.450 & 3.727 & 3.480 & 3.040 \\
\hline Error(SC) $\rightarrow$ & 1.826 & 0.072 & 2.796 & 1.462 & 4.643 & 5.084 & 3.984 & 2.372 \\
\hline
\end{tabular}


Table 2. $E(S C)$ and $E(R C)$ percent error for systems of 10000 storage locations

\begin{tabular}{|c|c|c|c|c|c|c|c|c|}
\cline { 2 - 9 } \multicolumn{1}{c|}{} & \multicolumn{7}{c|}{ Percent error between discrete and continuous retrieval times Error(RC) } \\
\hline $\mathrm{M}$ & \multicolumn{3}{|c|}{50} & \multicolumn{5}{c|}{100} \\
\hline$(\mathrm{N} 1 ; \mathrm{Nh})$ & $(40 ; 5)$ & $(10 ; 20)$ & $(13 ; 15)$ & $(14 ; 14)$ & $(5 ; 20)$ & $(15 ; 7)$ & $(9 ; 12)$ & $(10 ; 10)$ \\
\hline $\mathrm{b}$ & 0.125 & 0.5 & 0.866 & 1 & 0.25 & 0.466 & 0.75 & 1 \\
\hline$\rho$ & 0.113 & 1.142 & 1.001 & 0.931 & 0.749 & 0.303 & 0.632 & 0.555 \\
\hline 1 & 0.128 & 1.233 & 1.083 & 1.009 & 0.818 & 0.333 & 0.693 & 0.609 \\
\hline 0.9 & 0.135 & 1.283 & 1.125 & 1.052 & 0.857 & 0.349 & 0.728 & 0.640 \\
\hline 0.85 & 0.143 & 1.338 & 1.180 & 1.099 & 0.901 & 0.368 & 0.767 & 0.675 \\
\hline 0.8 & 0.151 & 1.397 & 1.230 & 1.150 & 0.948 & 0.388 & 0.810 & 0.713 \\
\hline 0.75 & 0.159 & 1.461 & 1.294 & 1.205 & 1.001 & 0.411 & 0.858 & 0.756 \\
\hline 0.7 & 0.181 & 1.610 & 1.433 & 1.335 & 1.127 & 0.465 & 0.975 & 0.859 \\
\hline 0.6 & 0.212 & 1.796 & 1.608 & 1.500 & 1.289 & 0.537 & 1.128 & 0.996 \\
\hline 0.5 & 0.265 & 2.040 & 1.842 & 1.719 & 1.508 & 0.636 & 1.339 & 1.185 \\
\hline 0.4 & 0.384 & 2.393 & 2.183 & 2.043 & 1.820 & 0.782 & 1.650 & 1.466 \\
\hline 0.3 & 0.008 & 2.796 & 1.914 & 1.462 & 3.738 & 0.268 & 2.919 & 1.885 \\
\hline Error(SC) $\rightarrow$ & & & & & & \\
\hline
\end{tabular}

Table 3. $E(\mathrm{SC})$ and $E(\mathrm{RC})$ percent error for systems of 10000 storage locations

\begin{tabular}{|c|c|c|c|c|}
\cline { 2 - 5 } \multicolumn{1}{c|}{} & \multicolumn{4}{|c|}{$\begin{array}{c}\text { Percent error between discrete and continuous retrieval times } \\
\text { Error(RC) }\end{array}$} \\
\hline $\mathrm{M}$ & \multicolumn{4}{c|}{8} \\
\hline$(\mathrm{Nl} ; \mathrm{Nh})$ & $(15 ; 80)$ & $(50 ; 25)$ & $(30 ; 40)$ & $(35 ; 35)$ \\
\hline $\mathrm{b}$ & 0.187 & 0.5 & 0.75 & 1 \\
\hline$\rho$ & 1.054 & 0.647 & 1.336 & 1.198 \\
\hline 1 & 1.522 & 1.096 & 1.786 & 1.647 \\
\hline 0.9 & 1.846 & 1.414 & 2.101 & 1.962 \\
\hline 0.85 & 2.233 & 1.793 & 2.480 & 2.341 \\
\hline 0.8 & 2.694 & 2.242 & 2.931 & 2.782 \\
\hline 0.75 & 3.238 & 2.786 & 3.460 & 3.320 \\
\hline 0.7 & 4.701 & 4.210 & 4.882 & 4.739 \\
\hline 0.6 & 6.860 & 6.343 & 6.996 & 6.865 \\
\hline 0.5 & 10.137 & 9.620 & 10.207 & 10.079 \\
\hline 0.4 & 15.123 & 14.578 & 15.128 & 14.992 \\
\hline 0.3 & 1.057 & 0.136 & 0.996 & 0.660 \\
\hline Error(SC) $\rightarrow$ & & &
\end{tabular}

On the other hand, the calculation of the gap for retrieval models is necessary when changing the load rate, because it is clear that the retrieval of an item will not take the same time for a full system compared to an emty system (it changes when the shape factor changes, the bins depth changes, or the load rate chanes).

Concerning the numerical simulation results, we will first, focus on those related to storage. In a first place, we notice that the more $\mathrm{M}$ decreases the more the error decreases, which is equivalent to say that the larger the face of the rack is, the closer discrete and continuous models are. Which is expectable since the more the face of the rack grows the more its assimilation to an infinity of points is consistent. It can be verified by comparing, for example, $1.462 \%$ and $2.372 \%$ (Table 2, fourth and last column, last row) which for the same size and identical shape factors, but with different $\mathrm{M}$ give different errors.

Furthermore, it should also be noticed that for small shape factors associated with cases when $\mathrm{N}_{1}$ is greater than $\mathrm{N}_{\mathrm{h}}$, this error falls considerably. It can be noticed in the Fig. 4., since for the same system size and the same value of $\mathrm{M}$, the error decreases when $\mathrm{N}_{1}$ is greater than $\mathrm{N}_{\mathrm{h}}$, this is due to the fact that on each rack face one column out of two is dedicated either for storage or retrieval and conversely in the opposite face. Consequently, when the value of $\mathrm{N}_{1}$ increases the aproximation that the continuous model is based on, is more relevant, since it considers the rack face as a surface of infinity of points.

On the other hand, we are also interested in the behavior of these models for the retrieval transactions, according to the variation of the systems sizes, their configurations and their load rates.

First, for small systems (Table 1), the error seems to be larger, and increases with the decrease of the load rate, since the more the system empties the less the approximation $M \cdot \rho \approx M^{\prime}$ is precise. This means that the larger is the system size, the less the variation of $\rho$ will negatively affect the concordance between the two models.

This can be noticed in Fig. 4 and 5, where the error of ERC decreases when the load rate increases. Another important point deserves to be emphasized; since unlike storage models, those of retrieval are closer to each other when $M$ increases, as this increase counterbalances the effect of the load rate decrease in the approximation mentioned above (Table 3 in comparison with Table 4). This variation appears clearly in Fig. 5, when for the same system size, when $M$ decreases the error increases.

\section{CONCLUSION AND DISCUSSION}

In the previous sections, mathematical models for storage and retrieval operations were presented. These 
models were developed according to two approaches, namely the continuous and discrete ones. The discrete models are more faithful to the system behavior, since their calculation is made by considering all the possible cases, while the continuous models are based on a couple of approximations. However, even if they are less precise, the closed-form continuous models are much more easy to use in performance investigations, system comparison, design optimization etc. Consequently, their accuracy compared to the discrete models need to be established to know how well they can be used for this kind of investigations. This accuracy was studied through simulation, and the gap variations were discussed according to different parameters. The continuous models have shown that they are quite accurate in general. Furthermore, the main points of this analyses can be summarized as follow:

-The gap is in the most common cases very small (The maximum is reached for the smallest system and when the load rate is very low, $22,58 \%$ for a 100 storage segments system and $\rho=0.3$ ).

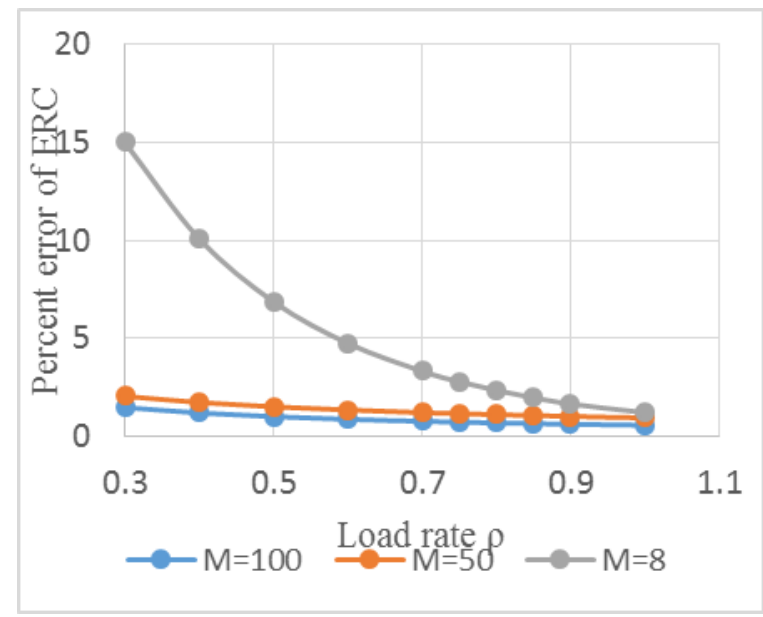

Figure 2. Percent error of ERC according to $p$ for a system size of $\mathbf{1 0 0 0 0}$ storage emplacements for different values of M

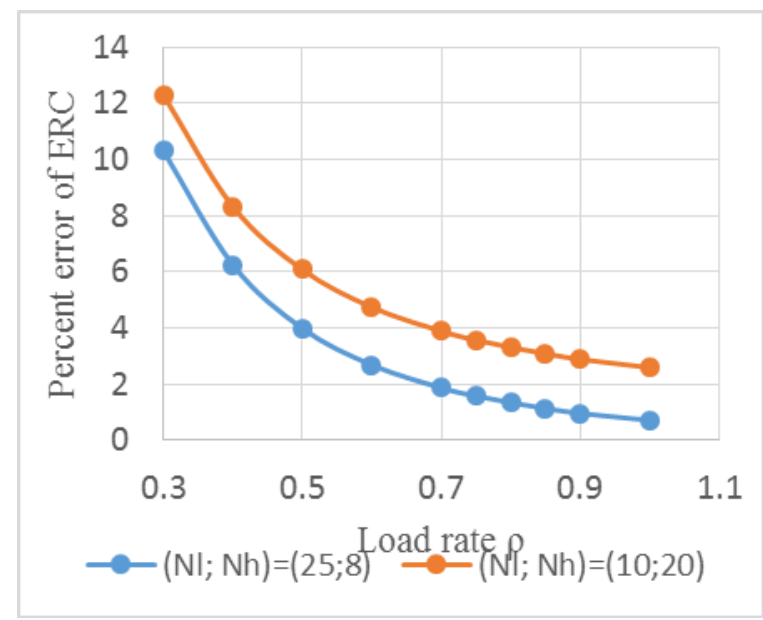

Figure 3. Percent error of ERC according to $p$ for a system size of $\mathbf{1 0 0 0 0}$ storage emplacements for same value of $M$

-For storage transactions, the more $\mathrm{M}$ decreases the more the error decreases, even if the shape factor is the same.
-For small shape factors, when $\mathrm{N}_{1}$ is greater than $\mathrm{N}_{\mathrm{h}}$, the gap falls considerably.

-For retrievals, the more the system is small the more the variation is large. However, these small systems rarely exist in the industry.

-When comparing retrieval equations, it appears that the error increases when the load rate decreases.

-Unlike storage equations, the retrieval ones are more close to each other when $M$ increases, and this by counterbalancing the load rate decrease.

-When looking on the overall given data from the simulation, for the different transactions with varying the multiple parameters, it appears that a shape factor near to 0.33 gives the lowest numerical variations between the two models.

According to these results, we can notice that the two models are quite close to each other. And the cases where the variation is too large, are not relevant, since these cases seldom exist (such small systems are very rare and $\mathrm{AS} / \mathrm{RSs}$ run in steady state on a load rate between 0.7 and 0.85 , namely the zone of actual operation [27]). That said, different cases according to the system shape and the running parameters could be studied and some of them highlighted, when the equations were the most accurate, in order to be used according to needs and purposes.

Finally, we can say that the presented closed-form models are easy to calculate due to their simplistic forms compared to discrete models. Moreover, these models are extremely practical in term of computation time, since discrete models require extensive computation time. The presented closed-form traveltime expressions developed in this paper are highly applicable in industry investigations and can be used as basis for further research leads. These models can be used to (1) establish performance standards for existing AS/RS, (2) conduct comparative studies for different AS/RS types while facing same conditions and operational constraints, (3) performance throughput evaluation for alternative design configurations or technical characteristics alternatives (machines speed for example), and (4) storage techniques comparison to improve system performances, etc. Thus, the presented results, as well as the developed closed-form expressions, are highly applicable to industry by virtue of their simplistic, yet accurate, formats.

However, the developed models can be improved, since not all the variations that the system faces are taken into consideration. We can cite for example the variations due to accelerations/decelerations of the $S / R$ machines, which may impact the overall cycle time of the system. The influence of this variation may vary according to the systems dimensions and the used technology ( $\mathrm{S} / \mathrm{R}$ machines motors). Also generalized models can be established when considering dual and single cycle occurrence probability, since in our paper we presented models that certainly consider the systemic aspect of the AS/RS, but where only single cycles were considered. Furthermore, our models can be used for further researches to develop more elaborated models, or can be combined with energy consumption models and even investment and usage cost models for 
example, to establish general multi-criteria models that can be used for multi-objective optimization.

Using the presented models, future works may also focus on performance evaluation and systems comparison while having a reasonable background that can lead to a better understanding of such systems.

\section{APPENDICES}

Appendix A: Discrete storage time model for each machine

According to [45] and since uniform distribution storage policy is considered:

$$
E S C_{\text {Machine } 1}^{D}=E(X)
$$

$X$ is a uniformly distributed variable, its support is:

$$
\operatorname{Sup}(X)=\left\{W_{i, j} / i \epsilon\left\{1 \ldots \frac{N_{l}}{2}\right\} \text { and } j \epsilon\left\{1 \ldots N_{h}\right\}\right\}
$$

Since a storage operation is simply a round trip between the P/D station and the storage location:

$$
W_{i, j}=2 S_{i, j}
$$

Because the Tchebychev distance is considered:

$$
S_{i, j}=\max \left(2(i-1) t_{h}^{\prime}+l ;(j-1) t_{v}^{\prime}+h\right)
$$

We have 2(i-1) because of assumption $A_{1}$.

For simplifications we consider $l=t_{h}$ and $h=t_{v}{ }_{v}$

$$
S_{i, j}=\max \left((2 i-1) t_{h}^{\prime} ; j t_{v}^{\prime}\right)
$$

On the other hand:

$$
\begin{aligned}
& E(X)=\frac{1}{\operatorname{Card}(\operatorname{Sup}(X))} \sum_{i=1}^{\frac{N_{l}}{2}} \sum_{j=1}^{N_{h}} W_{i, j} \\
& \operatorname{Card}(\operatorname{Sup}(X))=\operatorname{Card}(\operatorname{Sup}(i)) \cdot \operatorname{Card}(\operatorname{Sup}(j))
\end{aligned}
$$

Therefore, we have:

$$
E(X)=\frac{2}{N_{l} N_{h}} \sum_{i=1}^{\frac{N_{l}}{2}} \sum_{j=1}^{N_{h}} 2 S_{i, j}
$$

Finally:

$E S C_{\text {Machine } 1}^{D}=\frac{2}{N_{l} N_{h}} \sum_{i=1}^{\frac{N_{l}}{2}} \sum_{j=1}^{N_{h}} 2 \max \left((2 i-1) t_{h}^{\prime} ; j t_{v}^{\prime}\right)$

According to assumption $A_{1}$, by symmetry we find:

$\operatorname{ESC}_{\text {Machine 2 }}^{D}=\frac{2}{N_{l} N_{h}} \sum_{i=1}^{\frac{N_{l}}{2}} \sum_{j=1}^{N_{h}} 2 \max \left(2 i t_{h}^{\prime} ; j t_{v}^{\prime}\right)$

Appendix B: Discrete retrieval time models for each machine
1-OP1: The machines work independently (product on the first position).

This case is analog to a storage operation, since the travel is simply a round trip between the P/D station and the retrieval location.

On the other hand, according to assumption $\mathrm{A}_{1}$ we have:

$$
\begin{aligned}
& E R C_{O P 1 / \text { Machine } 1}^{D}=E S C_{\text {Machine } 2}^{D} \\
& E R C_{O P 1 / \text { Machine } 2}^{D}=E S C_{\text {Machine } 1}^{D}
\end{aligned}
$$

Therefore:

$E R C_{O P 1 / \text { Machine } 1}^{D}=\frac{2}{N h N l} \sum_{i=1}^{\frac{N l}{2}} \sum_{j=1}^{N h} 2 \max \left(2 i t_{h}^{\prime} ; j t_{v}^{\prime}\right)$

$E R C_{O P 1 / \text { Machine } 2}^{D}=\frac{2}{N h N l} \sum_{i=1}^{\frac{N l}{2}} \sum_{j=1}^{N h} 2 \max \left((2 i-1) t_{h}^{\prime} ; j t_{v}^{\prime}\right)$

2-OP2: The machines work together (product is not on the first position).

According to Bozer and White [45] and since uniform distribution storage policy is considered:

$$
E R C_{O P 2 / \text { Machine } 1}^{D}=E(Y)
$$

$Y$ is a uniformly distributed variable, its support is:

$$
\operatorname{Sup}(Y)=\left\{Z_{i, j} / i \epsilon\left\{1 \ldots \frac{N_{l}}{2}\right\} \text { and } j \epsilon\left\{1 \ldots N_{h}\right\}\right\}
$$

In this case, the retrieval operation is a round trip between the P/D station and the retrieval location, in addition to restoring operations to reach the desired item:

$$
Z_{i, j}=2 R_{i, j}+E\left(Q_{i, j}\right)
$$

$E(Q i, j)$ is the average restocking time for the bin $(i ; j)$, $Q_{i, j}$ is a uniformly distributed variable, its support is :

$$
\begin{aligned}
\operatorname{Sup}\left(Q_{i, j}\right) & =\left\{\begin{array}{c}
2(k-1) t_{p}^{\prime} / k \epsilon\left\{2 \ldots m_{2 i, j}\right\}, \\
i \epsilon\left\{1 \ldots \frac{N_{l}}{2}\right\} \text { and } j \epsilon\left\{1 \ldots N_{h}\right\}
\end{array}\right\} \\
E\left(Q_{i, j}\right) & =\frac{1}{\operatorname{Card}(\operatorname{Sup}(Q))} \sum_{2}^{m_{2 i, j}} 2(k-1) t_{p}^{\prime} \\
E\left(Q_{i, j}\right) & =\frac{2}{m_{2 i, j}-1} \sum_{1}^{m_{2 i, j}-1} k t_{p}^{\prime} \\
E\left(Q Q_{i, j}\right) & =\frac{2}{m_{2 i, j}-1} \frac{\left(m_{2 i, j}\right)\left(m_{2 i, j}-1\right)}{2} t_{p}^{\prime} \\
E\left(Q_{i, j}\right) & =m_{2 i, j} t_{p}^{\prime}
\end{aligned}
$$

Because the Tchebychev distance is considered:

$$
R_{i, j}=\max \left((2 i-1) t_{h}^{\prime}+l ;(j-1) t_{v}^{\prime}+h\right)
$$

We have 2(i-1) because of assumption $A_{1}$. 
For simplifications we consider $l=t_{h}^{\prime}$ and $h=t_{v}^{\prime}$

$$
R_{i, j}=\max \left(2 i t_{h}^{\prime} ; j t_{v}^{\prime}\right)
$$

On the other hand:

$$
\begin{aligned}
& E(Y)=\frac{1}{\operatorname{Card}(\operatorname{Sup}(Y))} \sum_{i=1}^{\frac{N_{l}}{2}} \sum_{j=1}^{N_{h}} Z_{i, j} \\
& \operatorname{Card}(\operatorname{Sup}(Y))=\operatorname{Card}(\operatorname{Sup}(i)) \cdot \operatorname{Card}(\operatorname{Sup}(j))
\end{aligned}
$$

Therefore, we have:

$$
E(Y)=\frac{2}{N_{l} N_{h}} \sum_{i=1}^{\frac{N_{l}}{2}} \sum_{j=1}^{N_{h}}\left(2 R_{i, j}+E\left(Q_{i, j}\right)\right)
$$

Finally:

$E R C_{O P 2 / \text { Machine } 1}^{D}=\frac{2}{N_{l} N_{h}} \sum_{i=1}^{\frac{N_{l}}{2} N_{h=1}}\left(2 \max \left(2 i t_{h}^{\prime} ; j t_{v}^{\prime}\right)+m_{2 i, j} t_{p}^{\prime}\right)$

We have that $t_{p}^{\prime}=\max \left(t_{h}^{\prime} ; t_{v}^{\prime}\right)$

$E R C_{O P 2 / \text { Machine } 1}^{D}=\frac{2}{N_{l} N_{h}} \sum_{i=1}^{\frac{N_{l}}{2} N_{h}}\left(2 \max \left(2 i t_{h}^{\prime} ; j t_{v}^{\prime}\right)+\right.$

$\left.+m_{2 i, j} \max \left(t_{h}^{\prime} ; t_{v}^{\prime}\right)\right)$

According to assumption $A_{1}$, by symmetry we find:

$E R C_{O P 2 / \text { Machine } 2}^{D}=\frac{2}{N_{l} N_{h}} \sum_{i=1}^{\frac{N_{l}}{2} N_{h=1}}\left(2 \max \left((2 i-1) t_{h}^{\prime} ; j t_{v}^{\prime}\right)+\right.$

$\left.+m_{2 i-1, j} \max \left(t_{h}^{\prime} ; t_{v}^{\prime}\right)\right)$

Appendix C: Discrete retrieval time model for the whole system in OP2

From (8), (11) et (12) we have:

$$
\begin{aligned}
& E R C_{O P 2}^{D}=\frac{1}{2}\left(E R C_{O P 2 / \text { Machine } 1}^{D}+E R C_{O P 2 / \text { Machine } 2}^{D}\right) \\
& E R C_{O P 2 / \text { Machine } 1}^{D}=\frac{2}{N h N l} \sum_{i=1}^{\frac{N l}{2}} \sum_{j=1}^{N h}\left(2 \max \left(2 i t_{h}^{\prime} ; j t_{v}^{\prime}\right)+\right. \\
& \left.+m_{2 i ; j} \max \left(t_{h}^{\prime} ; t_{v}^{\prime}\right)\right) \\
& E R C_{O P 2 / \text { Machine } 2}^{D}=\frac{2}{N h N l} \sum_{i=1}^{\frac{N l}{2}} \sum_{j=1}^{N h}\left(\begin{array}{l}
2 \max \left((2 i-1) t_{h}^{\prime} ; j t_{v}^{\prime}\right)+ \\
+m_{2 i-1 ; j} \max \left(t_{h}^{\prime} ; t_{v}^{\prime}\right)
\end{array}\right)
\end{aligned}
$$

By replacing $(\mathrm{C} 2)$ and $(\mathrm{C} 3)$ in $(\mathrm{C} 1)$ :

$$
E R C_{O P 2}^{D}=\frac{1}{2}\left(\begin{array}{l}
\frac{2}{N h N l} \sum_{i=1}^{\frac{N l}{2}} \sum_{j=1}^{N h}\left(2 \max \left(2 i t_{h}^{\prime} ; j t_{v}^{\prime}\right)+m_{2 i ; j} \max \left(t_{h}^{\prime} ; t_{v}^{\prime}\right)+\right. \\
\frac{2}{N h N l} \sum_{i=1}^{\frac{N l}{2}} \sum_{j=1}^{N h}\left(2 \max \left((2 i-1) t_{h}^{\prime} ; j t_{v}^{\prime}\right)+m_{2 i-1 ; j} \max \left(t_{h}^{\prime} ; t_{v}^{\prime}\right)\right)
\end{array}\right)
$$

Therefore:

$$
\begin{aligned}
& E R C_{O P 2}^{D}=\frac{1}{N_{h} N_{l}} \sum_{i=1}^{\frac{N_{l}}{2}} \sum_{j=1}^{N_{h}}\left(2 \max \left(2 i t_{h}^{\prime} ; j t_{v}^{\prime}\right)+\right. \\
& \left.+m_{2 i ; j} \max \left(t_{h}^{\prime} ; t_{v}^{\prime}\right)+2 \max \left((2 i-1) t_{h}^{\prime} ; j t_{v}^{\prime}\right)+m_{2 i-1 ; j} \max \left(t_{h}^{\prime} ; t_{v}^{\prime}\right)\right)
\end{aligned}
$$

We notice that this equation can be wrote this way:

$$
\begin{aligned}
& \operatorname{ERC}_{O P 2}^{D}=\frac{1}{N_{h} N_{l}} \sum_{i=1}^{\frac{N_{l}}{2}} \sum_{j=1}^{N_{h}} \sum_{k=0}^{1} 2 \max \left((i+k) t_{h}^{\prime} ; j t_{v}^{\prime}\right)+ \\
& +m_{(i+k) ; j} \max \left(t_{h}^{\prime} ; t_{v}^{\prime}\right)
\end{aligned}
$$

So by merging the two sums and changing the index:

$$
E R C_{O P 2}^{D}=\frac{1}{N_{h} N_{l}} \sum_{i=1}^{N_{l}} \sum_{j=1}^{N_{h}} 2 \max \left(i t_{h}^{\prime} ; j t_{v}^{\prime}\right)+m_{i, j} \max \left(t_{h}^{\prime} ; t_{v}^{\prime}\right)
$$

Appendix D: Continuous storage time model and retrieval time model for the whole system in OP2

We have that for the $S / R$ machine 1 , a storage is simply round trip between the $\mathrm{P} / \mathrm{D}$ station and the storage location:

$$
E S C_{\text {Machine } 1}^{C}=2 E\left(V_{1}\right)
$$

where $E\left(V_{1}\right)$ is the expected travel time from the P/D station and any storage location (and conversely), as calculated by Bozer and White [44]:

$$
E\left(V_{1}\right)=\frac{T}{2}\left(\frac{b^{2}}{3}+1\right)
$$

Then:

$$
E S C_{\text {Machine } 1}^{C}=T\left(\frac{b^{2}}{3}+1\right)
$$

It is exactly the same thing for the Machine 2:

$$
\operatorname{ESC}_{\text {Machine 2 }}^{C}=T\left(\frac{b^{2}}{3}+1\right)
$$

From (20) we have:

$$
E S C^{C}=\frac{E S C_{\text {Machine } 1}^{C} \cdot E S C_{\text {Machine 2 }}^{C}}{E S C_{\text {Machine 1 }}^{C}+E S C_{\text {Machine 2 }}^{C}}
$$

On the other hand:

$$
E S C_{\text {Machine } 1}^{C}=E S C_{\text {Machine } 2}^{C}=T\left(\frac{b^{2}}{3}+1\right)
$$

Then:

$$
\begin{aligned}
& E S C^{C}=\frac{E S C_{\text {Machine } 1}^{C} \cdot E S C_{\text {Machine 1 }}^{C}}{E S C_{\text {Machine 1 }}^{C}+E S C_{\text {Machine 1 }}^{C}}= \\
& =\frac{E S C_{\text {Machine 2. }}^{C} \cdot E S C_{\text {Machine 2 }}^{C}}{E S C_{\text {Machine 2 }}^{C}+E S C_{\text {Machine 2 }}^{C}}
\end{aligned}
$$




$$
\begin{aligned}
& E S C C^{C}=\frac{\left(E S C_{\text {Machine } 1}^{C}\right.}{2 E S C_{\text {Machine } 1}^{C}}=\frac{\left(E S C_{\text {Machine 2 }}^{C}\right)^{2}}{2 E S C_{\text {Machine } 2}^{C}} \\
& E S C^{C}=\frac{E S C_{\text {Machine } 1}^{C}}{2}=\frac{E S C_{\text {Machine 2 }}^{C}}{2}= \\
& =2 C S C_{\text {Machine 1 }}^{C}=2 C S C_{\text {Machine } 2}^{C}
\end{aligned}
$$

Finally:

$$
E S C^{C}=\frac{T}{2}\left(\frac{b^{2}}{3}+1\right)
$$

For retrieval in OP1, we have from (33) and (35)

$$
E R C_{O P 1 / \text { Machine } 1}^{C}=E R C_{O P 1 / \text { Machine } 2}^{C}=T\left(\frac{b^{2}}{3}+1\right)
$$

Then by replacing in (41):

$$
\begin{aligned}
& E R C_{O P 1}^{C}=\frac{E R C_{O P 1 / \text { Machine } 1}^{C} \cdot E R C_{O P 1 / \text { Machine } 1}^{C}}{E R C_{O P 1 / \text { Machine } 1}^{C}+E R C_{O P 1 / \text { Machine } 1}^{C}}= \\
& =\frac{E R C_{O P 1 / \text { Machine } 2}^{C} \cdot E R C_{O P 1 / \text { Machine } 2}^{C}}{E R C_{O P 1 / \text { Machine } 2}^{C}+E R C_{O P 1 / \text { Machine } 2}^{C}}
\end{aligned}
$$

$E R C_{O P 1}^{C}=\frac{\left(E R C_{O P 1 / \text { Machine } 1}^{C}\right)^{2}}{2 E R C_{O P 1 / \text { Machine } 1}^{C}}=$

$$
=\frac{\left(E R C_{O P 1 / \text { Machine } 2)^{2}}^{C}\right.}{2 E R C_{O P 1 / \text { Machine } 2}^{C}}
$$

$E R C_{O P 1}^{C}=\frac{E R C_{O P 1 / \text { Machine } 1}^{C}}{2}=\frac{E R C_{O P 1 / \text { Machine } 2}^{C}}{2}=$

$$
=2 C R C_{O P 1 / \text { Machine } 1}^{C}=2 C R C_{O P 1 / \text { Machine } 2}^{C}
$$

Finally:

$$
E R C_{O P 1}^{C}=\frac{T}{2}\left(\frac{b^{2}}{3}+1\right)
$$

Appendix E: Continuous retrieval time model for the whole system

We have from (45)

$$
\begin{gathered}
E R C^{C}=\frac{1}{M^{\prime}} \frac{T}{2}\left(\frac{b^{2}}{3}+1\right)+\left(1-\frac{1}{M^{\prime}}\right)\left(T\left(\frac{b^{2}}{3}+1\right)+M^{\prime} t_{p}^{\prime}\right) \\
E R C^{C}=\frac{1}{M^{\prime}} \frac{T}{2}\left(\frac{b^{2}}{3}+1\right)+\left(\frac{M^{\prime}-1}{M^{\prime}}\right)\left(T\left(\frac{b^{2}}{3}+1\right)+M^{\prime} t_{p}^{\prime}\right) \\
E R C^{C}=\frac{1}{M^{\prime}} \frac{T}{2}\left(\frac{b^{2}}{3}+1\right)+T\left(\frac{M^{\prime}-1}{M^{\prime}}\right)\left(\frac{b^{2}}{3}+1\right)+ \\
+\left(\frac{M^{\prime}-1}{M^{\prime}}\right) M^{\prime} t^{\prime} p \\
E R C^{C}=\frac{T}{M^{\prime}}\left(\frac{b^{2}}{3}+1\right)\left(\frac{1}{2}+\left(M^{\prime}-1\right)\right)+\left(M^{\prime}-1\right) t_{p}^{\prime}
\end{gathered}
$$

$$
E R C^{C}=\frac{T}{M^{\prime}}\left(\frac{b^{2}}{3}+1\right)\left(\frac{2 M^{\prime}-1}{2}\right)+\left(M^{\prime}-1\right) t_{p}^{\prime}
$$

We have that $M^{\prime}=\rho M$, therefore:

$$
E R C^{C}=\frac{T}{\rho M}\left(\frac{b^{2}}{3}+1\right)\left(\frac{2 \rho M-1}{2}\right)+(\rho M-1) t_{p}^{\prime}
$$

\section{REFERENCES}

[1] Kouloughli, S. (2014). Optimisation de systèmes automatisés de stockage/déstockage multi-allées et à racks glissants. (Doctoral dissertation).

[2] Zollinger, H. (1999). AS/RS application, benefits and justification in comparison to other storage methods: A white paper. Automated storage and retrieval systems production section of the Material handling industry of America..

[3] Malmborg, C. J. (2000). Interleaving models for the analysis of twin shuttle automated storage and retrieval systems. International Journal of Production Research, 38(18), 4599-4610.

[4] Grosse, E. H., Glock, C. H., \& Neumann, W. P. (2017). Human factors in order picking: a content analysis of the literature. International Journal of Production Research, 55(5), 1260-1276.

[5] Petersen, C. G. (1999). The impact of routing and storage policies on warehouse efficiency. International Journal of Operations \& Production Management, 19(10), 1053-1064.

[6] Glock, C. H., \& Grosse, E. H. (2012). Storage policies and order picking strategies in U-shaped order-picking systems with a movable base. International Journal of Production Research, 50(16), 4344-4357.

[7] Cardin, O., Castagna, P., Sari, Z., \& Meghelli, N. (2012). Performance evaluation of in-deep class storage for flow-rack AS/RS. International Journal of Production Research, 50(23), 6775-6791.

[8] Guerriero, F., Pisacane, O., \& Rende, F. (2015). Comparing heuristics for the product allocation problem in multi-level warehouses under compatibility constraints. Applied Mathematical Modelling, 39(23-24), 7375-7389.

[9] Chen, Z., Li, X., \& Gupta, J. N. (2016). Sequencing the storages and retrievals for flow-rack automated storage and retrieval systems with duration-of-stay storage policy. International Journal of Production Research, 54(4), 984-998.

[10] Kriehn, T., Schloz, F., Wehking, K. H., Fittinghoff, M. (2018). Impact of class-based storage, sequencing of retrieval requests and warehouse reorganisation on throughput of shuttle-based storage and retrieval systems. FME Transactions, 46(3), 320329.

[11]Hur, S., Lee, Y. H., Lim, S. Y., \& Lee, M. H. (2004). A performance estimation model for AS/RS by M/G/1 queuing system. Computers \& Industrial Engineering, 46(2), 233-241. 
[12] Ma, X., Zhao, L., Schulze, L. (2009). Performance of automated storage/retrieval systems under stochastic demand using queueing theory. International Journal of Innovative Computing, Information and Control, 5(12).

[13] Glock, C. H., Grosse, E. H., Elbert, R. M., \& Franzke, T. (2017). Maverick picking: the impact of modifications in work schedules on manual order picking processes. International Journal of Production Research, 55(21), 6344-6360.

[14]Hong, S., \& Kim, Y. (2017). A route-selecting order batching model with the S-shape routes in a parallel-aisle order picking system. European Journal of Operational Research, 257(1), 185-196.

[15] Malmborg, C. J. (2003). Design optimization models for storage and retrieval systems using rail guided vehicles. Applied Mathematical Modelling, 27(12), 929-941.

[16] Kuo, P. H., Krishnamurthy, A., \& Malmborg, C. J. (2007). Design models for unit load storage and retrieval systems using autonomous vehicle technology and resource conserving storage and dwell point policies. Applied Mathematical Modelling, 31(10), 2332-2346.

[17] Sari, Z., \& Bessnouci, N. H. (2012). Design \& modeling of a single machine flow rack AS/RS. IMHRC2012 proceeding. Gardanne, France.

[18] Guerriero, F., Musmanno, R., Pisacane, O., Rende, F. (2013). A mathematical model for the MultiLevels Product Allocation Problem in a warehouse with compatibility constraints. Applied Mathematical Modelling, 37(6), 4385-4398.

[19] Lerher, T. (2018). Warehousing 4.0 by using shuttlebased storage and retrieval systems. FME Transactions, 46(3), 381-385.

[20] Metahri, D., \& Hachemi, K. (2018). Retrievaltravel-time model for free-fall-flow-rack automated storage and retrieval system. Journal of Industrial Engineering International, 14(4), 807-820.

[21]Chen, Z., Li, X., \& Gupta, J. N. (2015). A bi-directional flow-rack automated storage and retrieval system for unit-load warehouses. International Journal of Production Research, 53(14), 4176-4188.

[22] De Koster, R. M. B., Le-Duc, T., \& Yugang, Y. (2008). Optimal storage rack design for a 3dimensional compact AS/RS. International journal of production research, 46(6), 1495-1514.

[23] Bessenouci, H. N., Sari, Z., \& Ghomri, L. (2012). Metaheuristic based control of a flow rack automated storage retrieval system. Journal of Intelligent Manufacturing, 23(4), 1157-1166.

[24] Kuo, P. H., Krishnamurthy, A., \& Malmborg, C. J. (2008). Performance modelling of autonomous vehicle storage and retrieval systems using classbased storage policies. International Journal of Computer Applications in Technology, 31(3-4), 238-248.

[25] Ekren, B. Y., \& Heragu, S. S. (2010). Simulationbased regression analysis for the rack configuration of an autonomous vehicle storage and retrieval system. International Journal of Production Research, 48(21), 6257-6274.

[26] Chen, L., Langevin, A., \& Riopel, D. (2010). The storage location assignment and interleaving problem in an automated storage/retrieval system with shared storage. International Journal of Production Research, 48(4), 991-1011.

[27] Sari, Z., Saygin, C., \& Ghouali, N. (2005). Traveltime models for flow-rack automated storage and retrieval systems. The International Journal of Advanced Manufacturing Technology, 25(9-10), 979-987.

[28] Sari, Z., \& Hamzaoui, A. M. (2013). Optimization of a Single Machine Flow Rack AS/RS for Minimum Expected Travel Time. IFAC Proceedings Volumes, 46(7), 57-62.

[29] Hamzaoui, M. A., \& Sari, Z. (2015). Optimal dimensions minimizing expected travel time of a single machine flow rack AS/RS. Mechatronics, 31, 158-168.

[30] Ghomri, L., \& Sari, Z. (2015). Mathematical modeling of retrieval travel time for flow-rack automated storage and retrieval systems. IFACPapersOnLine, 48(3), 1906-1911.

[31]De Koster, R. M. B., Le-Duc, T., \& Yugang, Y. (2008). Optimal storage rack design for a 3dimensional compact AS/RS. International journal of production research, 46(6), 1495-1514.

[32] Xu, X., Gong, Y., Fan, X., Shen, G., \& Zou, B. (2018). Travel-time model of dual-command cycles in a $3 \mathrm{D}$ compact $\mathrm{AS} / \mathrm{RS}$ with lower mid-point $\mathrm{I} / \mathrm{O}$ dwell point policy. International Journal of Production Research, 56(4), 1620-1641.

[33]Lerher, T., Potrč, I., Šraml, M., \& Tollazzi, T. (2010). Travel time models for automated warehouses with aisle transferring storage and retrieval machine. European Journal of Operational Research, 205(3), 571-583.

[34] Gagliardi, J. P., Renaud, J., \& Ruiz, A. (2014). On sequencing policies for unit-load automated storage and retrieval systems. International Journal of Production Research, 52(4), 1090-1099.

[35] Borovinšek, M., Ekren, B. Y., Burinskienè, A., \& Lerher, T. (2017). Multi-objective optimisation model of shuttle-based storage and retrieval system. Transport, 32(2), 120-137.

[36] Accorsi, R., Bortolini, M., Gamberi, M., Manzini, R., \& Pilati, F. (2017). Multi-objective warehouse building design to optimize the cycle time, total cost, and carbon footprint. The International Journal of Advanced Manufacturing Technology, 92(1-4), 839-854.

[37] Kosanić, N. Ž., Milojević, G. Z., \& Zrnić, N. Đ. (2018). A survey of literature on shuttle based storage and retrieval systems. FME Transactions, 46(3), 400-409.

[38]Lerher, T., Ekren, B. Y., Dukic, G., \& Rosi, B. (2015). Travel time model for shuttle-based storage 
and retrieval systems. The International Journal of Advanced Manufacturing Technology, 78(9-12), 1705-1725.

[39] Ekren, B. Y., Akpunar, A., Sari, Z., \& Lerher, T. (2018). A tool for time, variance and energy related performance estimations in a shuttle-based storage and retrieval system. Applied Mathematical Modelling, 63, 109-127.

[40]Ekren, Y. B., Sari, Z., \& Rosi, B. (2015). Simulation analysis of shuttle based storage and retrieval systems. International Journal of Simulation Modelling, 14(1), 48-59.

[41]D’Antonio, G., De Maddis, M., Bedolla, J. S., Chiabert, P., \& Lombardi, F. (2018). Analytical models for the evaluation of deep-lane autonomous vehicle storage and retrieval system performance. The International Journal of Advanced Manufacturing Technology, 94(5-8), 1811-1824.

[42] Rajković, M., Zrnić, N., Kosanić, N., Borovinšek, M., \& Lerher, T. (2017). A Multi-Objective Optimization model for minimizing cost, travel time and $\mathrm{CO} 2$ emission in an AS/RS. FME Transactions, 45(4), 620-629.

[43]Chen, Z., \& Li, Y. (2016). Dual-Command Operation Generation in Bi-Directional Flow-Rack Automated Storage and Retrieval Systems with Random Storage Policy. In Proceedings of the 2015 Chinese Intelligent Systems Conference (pp. 125131). Springer, Berlin, Heidelberg.

[44]Chen, Z., \& Gupta, J. N. (2017) A three-step heuristic for bi-directional flow-rack AS/RS with duration-of-stay storage policy. 7th IESM Conference, October 11 - 13, 2017, Saarbrücken, Germany

[45] Bozer, Y. A., \& White, J. A. (1984). Travel-time models for automated storage/retrieval systems. IIE transactions, 16(4), 329-338.

\section{NOMENCLATURE:}

$\boldsymbol{E R}^{\boldsymbol{D}}$ Discrete expected retrieval time

$\boldsymbol{E} \boldsymbol{R} \boldsymbol{C}^{\boldsymbol{C}}$ Continuous expected retrieval time

$\boldsymbol{E S C}^{\boldsymbol{D}}$ Discrete expected storage time

$\boldsymbol{E S C}^{\boldsymbol{D}}$ Continuous expected storage time

$\boldsymbol{A S} / \boldsymbol{R S}$ Automated Storage and Retrieval System

$\boldsymbol{P} / \boldsymbol{D} \quad$ Pickup/Delivery

$\boldsymbol{S} / \boldsymbol{R} \quad$ Storage/Retrieval

$\boldsymbol{t}_{\boldsymbol{h}} \quad$ Required time for displacement between adjacent bins (horizontally) $\boldsymbol{t}_{v} \quad$ Required time for displacement between

$t_{v} \quad$ adjacent bins (vertically)

$\boldsymbol{t}_{\boldsymbol{v}} \quad$ Height in time of the rack

$\boldsymbol{t}_{\boldsymbol{h}} \quad$ Length in time of the rack

$\boldsymbol{M}$ Number of unit-load emplacements in each bin

$\boldsymbol{N}_{\boldsymbol{h}} \quad$ Number of bins in height

$N_{l} \quad$ Number of bins in length

$\boldsymbol{T} \quad$ Normalization factor, $T=\max \left(t_{v}, t_{h}\right)$

$\boldsymbol{B}$ Shape factor, $b=\frac{\min \left(t_{v}, t_{h}\right)}{\max \left(t_{v}, t_{h}\right)}$

$\boldsymbol{m}_{i, j} \quad$ Number of stored items in the bin $(i ; j)$

$\boldsymbol{H}$ distance in height separating the $\mathrm{P} / \mathrm{D}$ station and the lowest bin

$\boldsymbol{L}$ horizontal distance separating the P/D station

$\boldsymbol{L} \quad$ and the closest bin

$t_{m}^{\prime} \quad$ Required time for displacement between two paired bins

$\boldsymbol{N} \quad$ Number of unit-load emplacements in the

$N \quad$ whole system

$\rho \quad$ Load rate
МОДЕЛИ ЦИКЛУСНОГ ВРЕМЕНА КОД

ДВОСМЕРНОГ ПРОТОЧНОГ РЕГАЛА СА СИСТЕМОМ ЗА АУТОМАТСКО СКЛАДИШТЕЊЕ И УЗИМАЊЕ РОБЕ

\section{М.А. Хамзауи, 3. Сари}

Предмет истраживања је двосмерни проточни регал са системом за аутоматско складиштење и узимање робе о чему се од недавно пише у литератури. Приказани су модели који разматрају овај систем са холистичког аспекта да би се боље разумело како он функционише. Усвојени метод моделирања омогућава развијање затвореног система и лакше коришћење једначина којима се моделира складиштење и узимање робе за цео систем. Приказани су изведени непрекидни модели за оба поступка. Они имају једноставну примену у математичким истраживањима за оптимизацију, евалуацију проточности, упоређивање система, итд. Међутим, нису у потпуности поуздани код понашања реалног система. Ово је био разлог да се развију дискретни модели који су прецизнији и користе се као мерило поузданости континуираних модела. У том циљу је развијен сопствени софтвер а резултати су издвојени и анализирани. 